\title{
The Governance of Emerging Value Chains and their Impacts on Traditional Communities
}

\author{
Eliane Superti, PhD \\ Department of Philosophy and Human Science \\ Federal University of Amapá \\ Brazil \\ Lee Pegler, PhD \\ International Institute of Social Studies \\ Erasmus University Rotterdam \\ Netherland \\ Mayara M. Vasconcelos Araujo, Msc \\ Postgraduate Program in Environmental Law and Public Policy \\ Federal University of Amapá \\ Brazil
}

\begin{abstract}
This article explores the effect of an evolving global value chain $(G V C)$ on the livelihoods and labor processes of traditional communities, a theme of great conjecture within the literature. We review the impact of the new surge of demand for açaí within four traditional communities in Amapá, along with their production processes and work divisions within a specific understanding of their sense of territory. The research was conducted with field work involving participant observation, interviews, questionnaires and photographic records. The results allowed detailing the actors, the organization, the (informal) contractual process and the form of governance within the chain. The paper highlights how rising demand creates new conflicts and uncertainties for chain governance, and that this is directly linked to the nature of contractual informality and communal property rights. This adds to existing concerns with respect to the prospect of communities/labor gains (social upgrading) as a result of GVC insertion.
\end{abstract}

Keywords: GVCs; açaí; governance; traditional communities.

\subsection{Introduction}

Production of açaí is expanding significantly, along with its consumer market. According to Cialdella and Alves (2014), the dynamism of this market is mainly explained by two factors: urbanization in the Amazon, which increases demand from traditional consumers, and promotion of açaí as a "health food." These authors note that two-thirds of production is consumed in the Amazon, but exports to other states and the international market continue to grow (CIALDELLA AND ALVES, 2014). Santana and Costa (2008) note that the dynamic of the market for this fruit pushed demand higher than supply, even during the harvest period. Over the past fifteen years production of açaí has become one of the largest and most important socioeconomic activities in the region, according to data from IBGE (2016), and açaí is a significant product of non-timber plan text activism in northern Brazil.

Açaí is mainly extracted in floodplain areas of the Amazon River estuary, but irrigated plantations also exist in upland areas. Pará is the state that leads production in the country, followed by Amazonas, Maranhão and Acre. While the state of Amapá is currently the fifth-largest producer of this fruit (IBGE, 2016), production in this case is strategic, as it takes place during the off-season of the main producer, state of Pará. Production of açaí in Amapá is mostly extractive, and is carried out by traditional communities (CARVALHO, 2010). With the arrival of companies to export and process fruit pulp in the mid-2000s, this production became part of the global value chain. These companies that operate in the state do not cultivate the fruit, but make local sales arrangements with transporters or middlemen and producers. 
The local extractivists who participate in these commercial arrangements include members of quilombos, communities originally founded by escaped slaves. By harvesting açaí and making local arrangements to sell this product to exporters, these communities began to integrate the global chain and redefine dynamics, power relations, and socioeconomic interactions related to the use of territory, work, and the process of commercializing açaí.

In Brazil, quilombola communities are considered traditional self-designated social groups that make themselves known through their notions of belonging, memories of their historical trajectory, and the movement of social forces and organizational instances that comprise them(LEITE, 2010). The Palmares Cultural Foundation, a public institution linked to the Ministry of Culture, grants official recognition to quilombola communities, allowing them access to specific federal social programs.

In a 2013 survey of açaí producers in Amapá, we identified four quilombola communities certified by the Palmares Cultural Foundation whose main economic activity derives from açaí; the survival of these communities is linked to the extraction and commercialization of the açaí fruit. These four communities are Cunani, located in the municipality of Calçoene, Porto do Abacate, located in Macapá, Nossa Senhora do Desterro, and Engenho do Matapí, both located in Santana. Along with the specific logics of social organization, these communities comprise the web of political and economic relations to the global value chain and its governance.

Figure 1 Location of selected communities

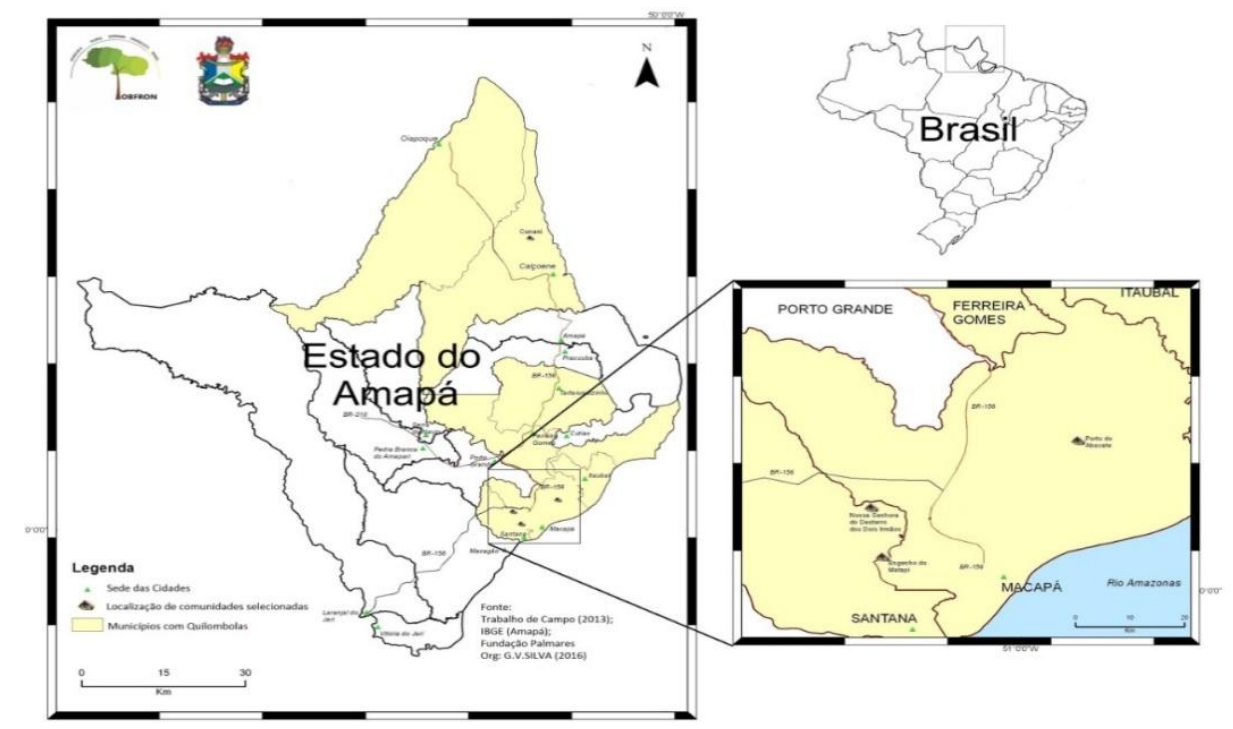

Source: Superti and Silva (2015)

This article discusses the participation of these four quilombola communities in the açaí productive chain which produces global value. Our objective was to understand the insertion of these communities, describe the agents in the chain, and to discuss the form of chain governance and its implications for potential social upgrading in these communities.

A value chain consists of activities that must be undertaken to produce, sell, or distribute a product or service. Each activity, which can be done individually or by several agents, is required to add value to the product or service so it can be offered in the consumer market. Global value chains are productive chains in which production is not concentrated in a single location or country, but rather in several countries. The activities along the chain are consequently fragmented and occur in several places, characterizing what Scherer (2014) points out as a geographic dispersion, but one that is ordered by production. According to Pegler (2009), analysis of global value chains is important to understand the level of insertion of an agent within these chains. Governance permits reflections on the socioeconomic and power relations engendered throughout the function of value chains.

The research underlying the arguments in this paper is based on field research conducted from 2013 to 2016, and consists of semi-structured interviews, documentary analysis, and bibliographic research. The reflections herein are structured by presenting and discussing the quilombola communities, describing the productive chain, and analyzing the governance present in the segment of the chain we investigated. 
Our analysis of the açaí production chain occurs "downstream," namely from primary production (fruit harvest) until the product arrives at the pulp processing/exporting company or the local market, passing through the middlemen and intermediaries who are responsible for most of these sales. The entire production chain will not be analyzed, because the production chain ends in other countries when the product is exported, and when it is sold locally the chain scatters among many small establishments; this would require other research efforts and would diverge from the objectives of this study. The main focus of this analysis is the governance present in the segment of the chain we studied, pointing out its limits and potentials.

\subsection{Quilombola communities and production of açaí.}

The formation of quilombola in Brazil was one of the forms of resistance to slavery, which was a source of labor in Brazil until 1888. The remnants of quilombola communities we know today derive from this resistance, but also from Black communities' struggles to survive in the lands they historically occupied and preserve their customs and traditions, which comprise significant cultural heritage.

According to Malcher (2009) the construction of the quilombola identity and preservation of its culture is directly linked to its territory. This is because the connection between quilombola communities and the land they occupy is not only an economic issue of cultivating land for survival, but also a guarantee that their daily habit, rites, and very existence will continue. Even in communities in which professional occupations have diversified and agriculture is no longer the only or the main source of sustenance, the living space (i.e., the territory occupied) is the space for their culture, and therefore fundamental for their maintenance.

The survival of these communities consequently depends on protection of their territory, as well as preservation of the environment and biodiversity. The fight for land rights has led these communities to organize themselves, join forces with other Black movements, and demand the recognition of their land rights from the state. Pressured by political and social forces, the Brazilian government granted rights to the quilombola communities, guaranteeing ownership of their lands in Article 68 of the Transitional Constitutional Provisions Act of the 1988 Federal Constitution ${ }^{1}$. Recognition of quilombola territories was much more than the materialization of land policy, since it implied a recovery of Afro-Brazilian culture. This policy allowed the formation of a new ethnic-based social cartography, based on Black ancestry in conjunction with resistance to historical oppression (TRECCANI, 2006).

State protection of quilombola communities is not protection of an individual or family nucleus. In this context, there is a basis for protection of an ethnic community, in other words, cultural basis. This protection extends beyond and issues, protecting the way of life, traditions, and customs which are linked to a certain territory and also safeguarding the environment.

Nevertheless, the realization of this right is far from a reality. It was only in 2007 that the federal government established the National Policy for the Sustainable Development of Traditional Peoples and Communities (PNPCT) through Decree 6040. This legislation defined these groups as "culturally differentiated, recognizing themselves as such and with their own forms of social organization, occupying and using territories and natural resources as a condition for their cultural, social, religious, ancestral and economic reproduction, using knowledge, innovations and practices generated and transmitted by tradition." Even with the implementation of this public policy, the process to regularize land ownership in favor of these communities is very slow. For example, out of the 28 communities our 2013 survey identified in Amapá as certified by the Palmares Cultural Foundation, only 4 had ownership of their lands. None of the communities investigated in this present study own their lands. More than 27 years after the ratification of the federal Constitution and nine years after the PNPCT, the Brazilian state has not yet been able to effectively respond to this important social demand.

The ways that traditional communities use their territory not only maintain the cohesion and culture of the group itself, but also link it to the society surrounding it and allow them to participate in the dynamics of the productive market. Surplus from activities such as farming, handicrafts, and extractivism goes to the market as a way of generating resources to maintain life, not to accumulate capital. Among most rural quilombola communities in Amapá, the main income-generating product is cassava flour, and other production or extractivism is only complementary.

\footnotetext{
1 "Final title shall be recognized for the remaining members of the former fugitive slave communities that are occupying their lands, and the State shall grant them the respective deeds." (Original Portuguese text: "Aos remanescentes das comunidades dos quilombos que estejam ocupando suas terras é reconhecida a propriedade definitiva, devendo o Estado emitir-lhes os títulos respectivos.") 
The four communities - Cunani, Nossa Senhora do Desterro, Engenho do Matapí, and Porto do Abacate examined in this study are exception, for them extractivism and sale of açaí is the main economic activity. Three of these communities were formed by groups of escaped Black slaves, while Nossa Senhora do Desterro was the result of migration in search of areas for subsistence agriculture. In all four communities the living conditions are very similar: they are located along rivers in hard-to-reach areas. Subsistence is the result of extractivism and small-scale agricultural production. Houses in these communities are mostly wooden and lack treated water and basic sanitation. Three communities have regular electricity, while Cunani only has electricity from a generator at night. Only Cunani has an elementary school and a health clinic, and the other communities do not have these social installations (Fieldwork, 2015).

The fieldwork data indicate that the communities are comprised of a rural population with low income and lowlevels of schooling. These families are not traditional nuclear families (father, mother and children) but rather extended family in a single household, extending from parents to grandchildren or great-grandchildren andsonsor daughters-in-law. Average monthly family income ranges from 1 to 2 minimum wage equivalents ${ }^{2}$ and is concentrated in months when açaíis harvested. During non-harvest months, families support themselves on savings from surplus from small-scale productionand financial aid from federal government. Adults generally completed elementary-level schooling and the children either leave the community to study or simply do not attend school, except for in Cunani, where children attend the school, but only through the fourth grade. Infrastructure in these communities is lacking basic public services such as treated water, sanitation, health, and education services. There is no public transportation, and in all of the communities the precariousness of river or land-based access is a serious challenge for sending açaí to market.

In all four communities, açaí production takes place during the Amazonian winter or rainy season, from March to July. The fruit is mostly harvested from native groves of açaí palms, and only in the Engenho do Matapí community has planting been attempted; around 7,000 trees were established, but the farmers claim that the cultivated trees did not grow as well as the native trees. Initially, the bunches of berries were small, only bearing fruit two years after the trees were planted. Large bunches only appeared after four years (Fieldwork, 2016). Management of native açaí palms, which could facilitate extraction and increase production, is also not common. Both the Cunani and Engenho do Matapí communities set aside small areas for experiments in this direction, both with the support of a state agency. According to residents of both communities, extraction is easier when the trees are managed since the trees are not as tall, and the quality of the fruit also improves.

The collective organization of the work which sustains these families is a highlight of the social organization of these quilombola communities. Men's and women's activities, however, are differentiated. During harvest in all the communities, families work together; relatives and friends with close ties, even those who live elsewhere, participate in extraction. In Nossa Senhora do Desterro and Engenho do Matapí, residents of nearby communities also help with this activity. People who do not live in the community receive a cash payment after the açaí is sold. These agreements are informal and are based on trust, which is fundamental in establishing economic relations within the communities. They are the result of friendship, reciprocity, and mutual advantage; if these ties are broken, they are difficult to re-establish. Community members do not receive payments, but will have help when it is their turn to harvest their crops.

Harvesting together and inviting relatives and friends has a meaning that extends beyond simply expanding the workforce. Working together reinforces the sociability of the group and strengthens internal and external reciprocal ties. It also forces all partners, especially those who come from outside, to recognize the area that the community considers to be its property, along with familial subdivisions. The collective way of organizing work fuels the group's internal cohesion by connecting them in processes of cooperation and reciprocity. It also establishes links of trust and integration with other communities, and brings social recognition of the property that belongs to the community and each family group.

In terms of sexual division of the activities, the bunches of açaí berries are only removed from the trees by men; in Porto Abacate women also perform this task, but only when men are not present. Climbing the açaí palms to pick the fruit bunches is not a simple activity.

\footnotetext{
${ }^{2}$ In Brazil, the minimum wage is the lowest monetary payment defined by law that a worker must receive in a company in exchange for services.
} 
It requires knowledge from elder members of the community to find where there are more açaí groves in the forest, which trees produce better fruit (considering the time at which extraction takes place). The harvesters must also know how to make the rope loop known as apeconha, which holds both feet to facilitate climbing up the palm, and have good balance to cut the bunch and descend with it in hand.

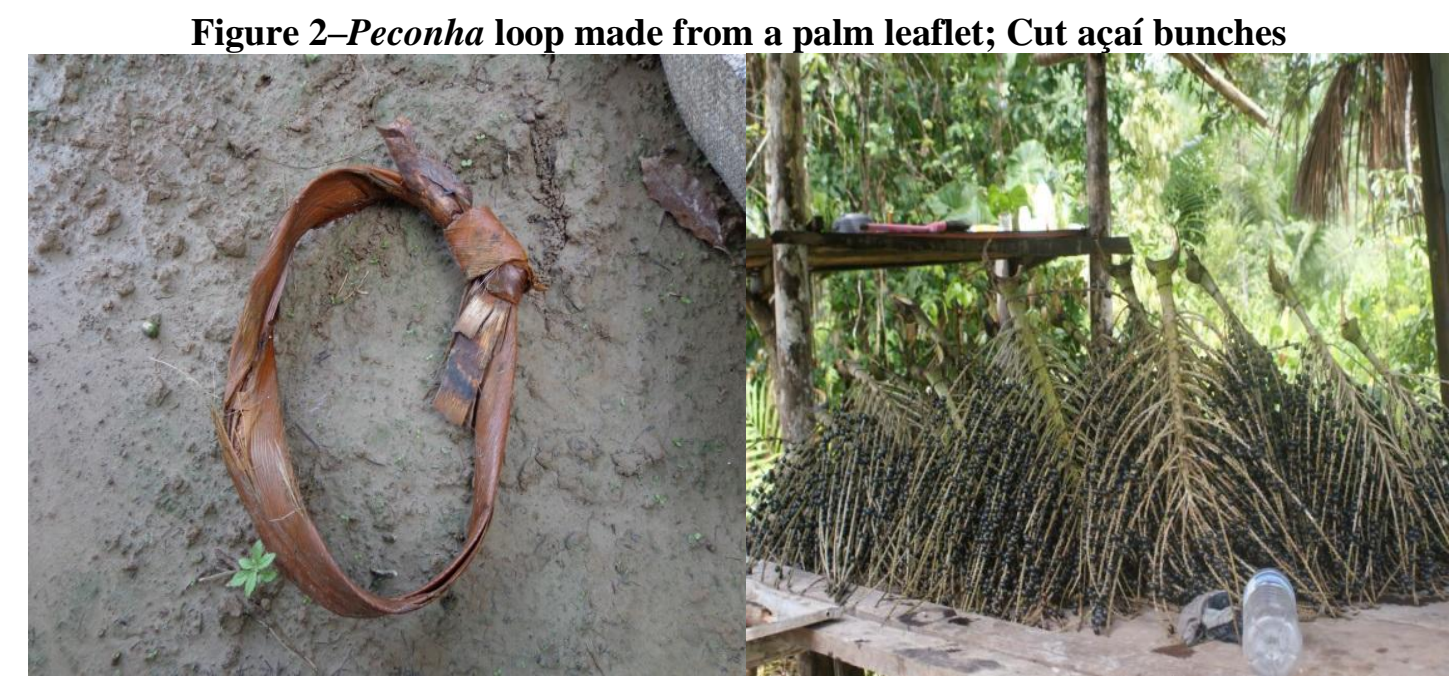

Source: Community of Porto Abacate, Fieldwork, 2013.

This traditional knowledge is handed down from one generation to the next. Young boys accompany their fathers and learn how to make the rope loop, climb smaller palms, and recognize the territory, identifying the best trees and becoming initiated into the work of the men. The same is true for the girls, who accompany their mothers, aunts, and older sisters who separate the fruit from the bunches and collect it. In this way, these children's work socialization is processed for their own lives in the future and for the community.

According to the peconheiros (as the men who climb the açaí palms using the loop are known), the work requires more technique than strength, but everyone considers this step the most grueling. Each peconheiro harvests about 8 to 10 15-kg sacks of açaí per day. The work does not stop with harvesting: once on the ground, the bunches are threshed (separating the fruit from the bunch structure using a stripping movement of the hands) on a canvas, cloth or mat so the fruit does not get wet or dirty. The sorted açaí is placed in baskets, cans, or bags for transport at the end of the process.

Since the fruit is mainly extracted from native groves, the entire process takes place in the forest, within the territory belonging to the communities. The mapping of the territory to identify the groves and the landmarks that delimit parcels belonging to each family and those that are shared are based on memories of the elders, which recall agreements between families, facts of community life like the clearing areas for agriculture, extractive activities or to prepare for hunting. The landmarks that define each family's area are symbolic and established through the shared social experience of the group. According to Cardoso and Cardoso $(2015$, p. 80);

In the Quilombola communities land is generally for common use. There are no clearly defined boundaries to each property. Land areas are associated to family groups who negotiate boundaries by means of symbolic markers. Subjects are linked to family groups via consanguinity or friendship ties. Thus, their right to use a space is guaranteed on the basis of their social relations.

Family land ownership is directly related to the group's socio-political organization, and is not understood as a commodity to be bought, sold, or used in the capitalist production of wealth. Nevertheless, their use of land is the main way families can measure income and participate in the productive market. Cardoso and Cardoso (2015, p. 80) point out that for quilombola families, "land is, above all, conceived as a source of resources to guarantee life." Work is the main element defining the division of territory between the families and attributing ownership.

Communities have different understandings about the collective ownership of their territories and the areas within that are exclusively used by each family. Ownership of this territory is linked to the original or previous occupation of geographical space which was used to constitute the elements that comprise the community's culture, while ownership of each family's section is defined by work. 
When a family (in agreement with the group) modifies nature, preparing the soil to cultivate crops, managing the acai, planting fruit trees, or building spaces for animals, this area becomes exclusively theirs to use. Within the territory, work delimits which space is common and which is for private use.

These two interpretations of ownership do not exclude or contradict each other; in fact, the former is broader and also involves work, but not only work. The latter interpretation establishes the right to privately use the area that already was collective property, but which was transformed by work. Both interpretations refer to classical theoretical readings on the origin of ownership present in Emilie Durkheim and John Locke. According to Locke (1988), ownership originated from work and formed the base of the organization of a society. Durkheim took a contrasting view, stating that the right to ownership did not originate only from work itself, since this would mean that establishment of the right to ownership considered only one element that did not historically reveal the origin of the ownership as a social fact. To Durkheim, the origin of land ownership was historically rooted in the notion of collective property and defined by the initial occupation. (DURKHEIM, 2002, p175). Clearly, while this article cannot delve farther into this theoretical debate, both views help us understand the way property is defined by communities.

To extract açaí, each family organizes the harvest in its area according to the time the fruit ripens and internal and external agreements to carry out this work. One community member may not work in another's area without permission, but it is common (especially in the community of Cunani) for one family to allow another to harvest from their property. This usually happens when a family is facing financial challenges or the amount of ripe fruit surpasses their capacity to extract it. In common areas, all community members can harvest freely. In these areas, work again defines ownership: the amount of fruit a family collects (along with those who provide the labor for this work via informal agreements) belongs to it.

The communities' face the most land conflicts in the common areas, which is a serious matter given the importance of land to the lives of community members. The main complaint in the Cunani community is the presence of teams of hired peconheiros that invade these areas, sometimes using violence. In the Engenho do Matapí community, conflict stems from the presence of some invaders who took overpart of the common areas and began to block the community from harvesting the fruit. Difficult access to both communities still protects them from more serious conflicts, and also applies to the Nossa Senhora do Desterro community, where we did not find land conflicts (Fieldwork, 2016). But the reality is much graver in the Porto Abacate community, which is located $47 \mathrm{~km}$ by highway from the state capital, Macapá. This community suffers from the activities of invaders who occupy a significant part of its lands. They mark out the occupied area and sell the land, speculating in the real estate market and bringing in new invaders, which in turn leads to the clearing of the forest and açaí groves (Fieldwork, 2015). Land conflicts are exacerbated by the government's inability (despite all the existing legislation) to demarcate and title land in favor of these communities. Furthermore, it is difficult for these communities to initiate and utilize judicial mechanisms to guarantee their land rights.

In the four studied communities, fears related to diminishing açaí production are a constant presence. This is because the income obtained from harvesting this fruit sustains the families throughout the year. They stock the groceries they need for the whole year, along with consumer goods like clothes, shoes, and home appliances. During the rest of the year they purchase little and supply their daily needs through small-scale farming or breeding animals, as well as hunting and fishing.

To summarize in terms of the implications of this situation for the subsequent consideration of governance and contractual relations in a growing market, two points can be made. First, the model of accumulation in these communities is what might be called "primitive accumulation" at best. It is subsistence-driven, but does generate some stocks of resources for future production. Second, under fairly stable conditions the local model of territory/property rights is communal for most things, but more clearly personally defined when it comes to specific tasks and work. Thus, land and the tenure of land (ownership rights) underscoring these relations and the sense of territory become the key point of conflict when more abrupt changes to resource use emerge. The following discussion of the broader chain, other actors, and contractual conditions further underscore these uncertainties in chain outcomes for producers and for others in a growing market.

\subsection{The Açaí chain extracted by the quilombola communities.}

Once the açaí fruits are harvested and packaged, they must be sold quickly, because the fruit oxidizes quickly and loses its quality. This is when an important agent, the middleman, enters the chain. 
This agent buys the açaí in the communities and resells it at "açaí fairs" where other merchants buy the fruit for blender shops (known as batedeiras ${ }^{3}$ ), companies, and resale. The middlemen usually maintain a close relationship with the families in the community. They visit and provide message services, bring things from the city that are "ordered" by community members, and take along people who need to travel. They also often anticipate amounts to be discounted when the product is sold. The middleman also generally provides the bags to pack the açaí and distributes them to the families.

In an interview with Ronaldo Silva, the main middleman in the Cunani community, he states that his intention is to maintain bonds of trust with the residents who always sell their production to him (Ronaldo Silva, field interview, 2015). There are no contracts or binding documents, but the trader usually makes an informal purchase agreement with the producing families. It is through agreements of trust that the community establishes its internal economic relations, and this logic also holds for the commercial arrangements along the açaí production chain.

Most of the açaí harvested in the community of Cunani is resold in Macapá at the Pedra do Santa Inês açaí fair (named for the location of the fair) and also in the municipality of Santana, at the fair in the port area. At the Pedra do Santa Inês,the fruit is sold every day to both the batedeiras and the factories ${ }^{4}$. The middleman Ronaldo Silva explained that there is no way to tell who the main buyers are in this type of sale, because there are many local batedeiras, and sales target them since they buy first and pay more to take the best berries -only the leftovers are sold to the factories. The middlemen do not deal directly with the factories; negotiations take place directly with the boatmen, ${ }^{5}$ who are hired by the factories to buy the fruit. According to the middleman, the boatmen profit most: "They are the ones who make the most money, they only do the negotiation." (Ronaldo Silva, field interview, 2015).

In Nossa Senhora do Desterro, the locals transport the açaí by boat to the small, rustic wooden port that provides access to the community. At the port, the middlemen wait to start the negotiation process. The main middleman who buys the açaí from the Nossa Senhora do Desterro community also trades with extractors from the Engenho do Matapí community, and is known as Seu Raimundo ["Mr. Raimundo"].

Seu Raimundo is a resident of the Engenho do Matapí community and also an açaí extractivist. Every year during the harvest period, in addition to harvesting the fruit, he buys the açaí from both communities and resells the product to an intermediary in Santana.

The intermediary is always the same person, Lindoval Santana. This sale between the two parties has been taking place for ten years; the middleman defines the price that the intermediary will pay.

Figure 3: Port area of Santana where the açaí is sold.

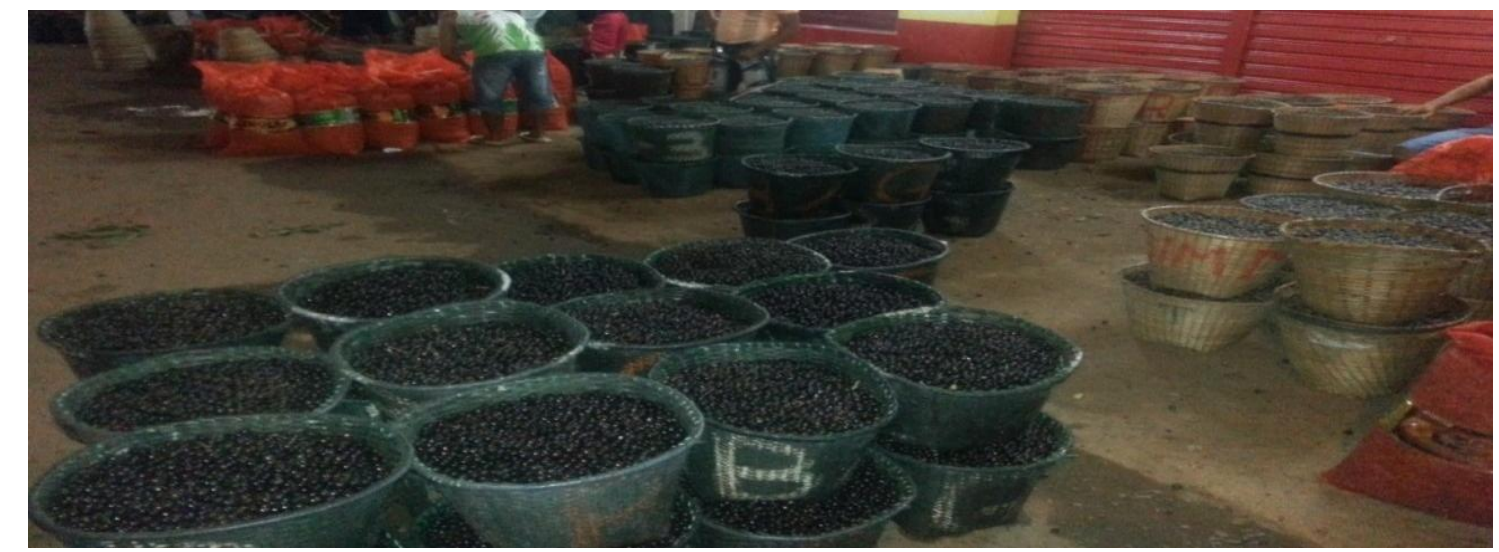

Source: Fieldwork, 2015.

\footnotetext{
${ }^{3}$ Batedeiras are local businesses that blend the açaí with water in their own machines, pack the product, and sell it to the final consumer.

${ }^{4}$ The middlemen call the companies that process the açaí pulp "factories."

${ }^{5}$ Boatmen are responsible for buying açaí for the processing and exporting companies; they are the agents between the company and the middlemen or producers. They are known as boatmen because they arrive by boat to make their purchases from the middlemen as well as riverside communities.
} 
As for sale to export company, Lindoval Santana (field interview, 2015) explained that these companies purchase the fruit by weight, in units of $13 \mathrm{~kg}$, which is what the traditional baskets or cans used for açaí hold. Santana stated that he has been working for the exporting company since it began operations in the region, but that he has no signed contract with them. He added that the work is informal and the entire process takes place by phone. He advises the company when the fruit arrives for sale and the company's boatman pick up the product.

When the fruit is sold, the company's boatman determines the price, and there is no space for negotiation. In order to purchase the açaí, the boatman also requires a certain quality standard, and consequently classifies the fruit.

In the community of Porto Abacate, the main middleman, Manoel Soares, buys açaí from all the communities located along the Pedreira River, and has been doing this work for six years. He picks up the açaí produced in the communities by boat, and resells it at the Pedra de Santa Inês fair.

\section{Figure 4: Pedra de Santa Inês Fair-Traditional Amazon baskets (paneiros) and 30kg sacks in the} background.

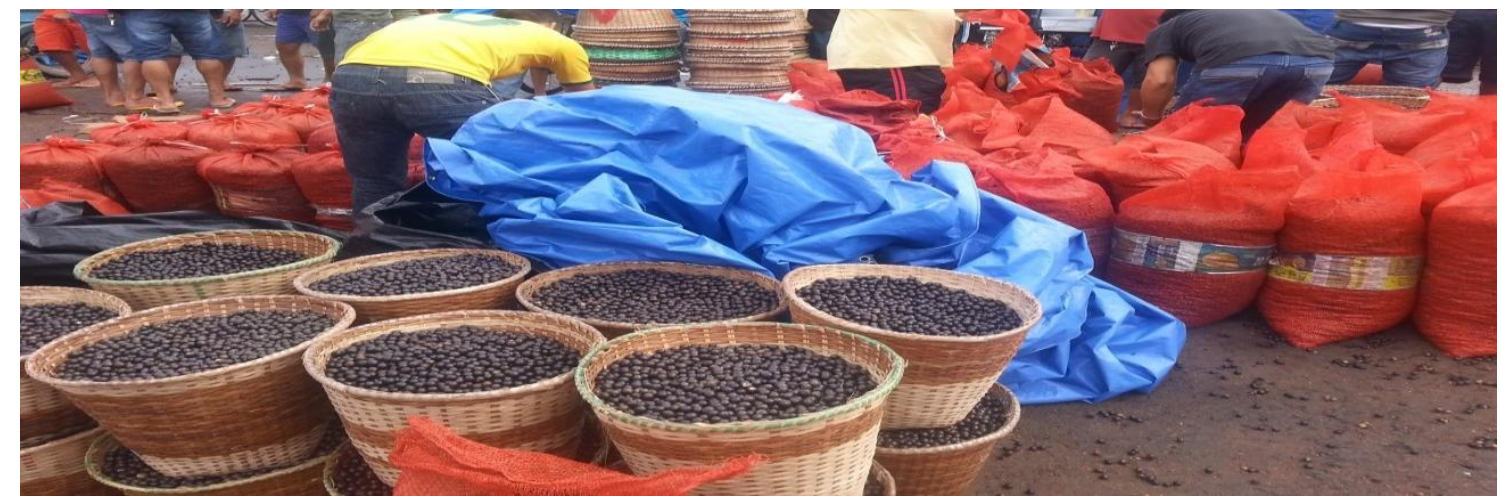

Source: Mayara Araujo,fieldwork, 2015.

The fruit is sold to batedeiras in the city of Macapá, and the remaining açaí is bought by the factories. In this way, explained the middleman, "what is left goes to the factories. (...) They are the only ones who buy it. (...) They take everything that is left over." (Manoel Soares, field interview, 2015).

According to the producers in all the communities we studied, when the fruit is sold it is the middlemen who determine the price. There is no negotiation with the local residents, and the communities do not have direct contact with the factories that buy part of their production. In practice, the middlemen are the agents who are present in the productive chain and are responsible for the sales transactions, and they conduct all the negotiations with the communities to purchase their production.

The boatman is the central agent in the commercial relations with the processing companies. His function is to buy, transport, and resell the açaí from the middlemen and producers to the companies. For the purposes of this analysis, we will consider the survey we conducted with a processing and exporting company ${ }^{6}$ located in Amapá. The company does not buy the açaí directly from the quilombola communities we studied that produce the fruit because they have the highest market price, according to the boatmen we interviewed. This assertion that the boatmen only buy what is left over after sales to the batedeiras was confirmed in the interview: "The company only authorizes us to buy what is left over, they can't buy the açaí and leave the batedeiras without the product" (Boatman 1, field interview, 2015).

Açaí purchases take place every day, and according to the boatmen, the sales price for the product is established according to the harvest and the amount of fruit available. They are the ones who define the price to be paid. For the exporting company, it does not matter if the boatman brings the açaí in sacks or in baskets, because the company purchases the fruit by weight. A defined price is paid for every $13 \mathrm{~kg}$ according to the harvest period, in addition to another previously defined amount for shipping. The boatmen unload the açaí at the company's dock. During the fieldwork (2015-2016), we identified 20 boatmen registered with the processing and export company. The company was created 10 years ago and has been active for 9 years.

\footnotetext{
${ }^{6}$ At the request of the representative, the names of the company, the representative, and the 3 boatmen who were authorized to give interviews will remain anonymous.
} 
Its production (estimated at 15,000 tons per year) is exported to the United States; this production is the processed fruit pulp and final consumer products such as juices, ice cream, and açaí powder capsules.

\subsection{Characteristics of the agents and governance present in the production chain.}

According to Carvalho (2010), the açaí production chain in the state of Amapá is made up of nine economic sectors: I - extractive production; II - rural retail; III - state wholesale; IV - urban retail; V -state processing; VI -the state processing industry; VII - state consumption; VIII - national consumption; and IX - international consumption. The quilombola communities we studied are inserted into this chain, and many of the agents are involved in more than one sector identified by this author.

The first step, extractive production, is carried out by those agents in the chain who collect the fruit and are known as agro-extractivists. In this specific study, these agents are residents of the quilombola communities.

According to Carvalho (2010), rural retail refers to the agents in the chain who buy the açaí directly from the producers and transport the fruit to the places (fairs) where it is sold. These agents are known as middlemen and transport the fruit over land or by river.

State wholesale is represented by the agents who market the fruit at the fairs (points of sale), which are mainly located in Macapá and Santana. These agents are the middlemen, and also the intermediaries who resell the production to the urban retailers who purchase for of the batedeiras, as well as the boatmen from the factories who buy from the fairs to resell to the factories -the point at which the production from the communities we studied enters the global chain.

For the author, the state processors are those agents known as batedeiras or amassadeiras (smashers). They process the fruit and resell the açaí blended with water directly to consumers in urban centers within the state.

The state processing industry is comprised of the industries that process and transform the fruit intended for domestic markets, as well as processing and exporting companies that also sell their products for international consumption.

Humphrey and Schmitz (2001), who analyze governance in global value chains, it is increasingly common for global value chains to be organized by global buyers. These global buyers dictate the rules, controlling and influencing production, even though they do not perform all of the necessary steps. But we found in the segment of the global açaí value chain we analyzed in Amapá, which involves the quilombola communities, that the global buyers (the exporting company) do not determine the rules of the production process and the commercialization at this point in time. The middlemen are much more present and are decisive agents of this process.

It is the middlemen who, in the context of the community, establish informal agreements, creating bonds of trust, commitment, and even dependence with the extractivists. In addition, the extractivists interviewed in all the analyzed communities stated that the prices are established by the rural retailers. They do not negotiate the price, but determine it according to supply and demand, there by defining the price of production. In this way they exercise strong power within the governance process in relation to other agents.

Based on the studies by Humphrey and Schmitz (2001) on governance in global value chains, the form of governance affecting quilombola communities is not established by the companies. There is a space for autonomy in the communities to define the time of harvest, rhythm, organization, and work process for extraction. But the power to define the price and sell the fruit is dictated by the middlemen and intermediaries. This drivesthe governance chain to the buyer, which is common in chains related to foodstuffs. Consequently, as chains evolve, the connection between buyer firms/agents (local as well as global) and initial producers (conditions) becomes clearer and more determinate. ${ }^{7}$

For Gereffi (2011, p.8), "Governance analysis allows one to understand how a chain is controlled and coordinated when certain actors in the chain have more power than others." In general, the concept of governance, regardless of the extent to which it is understood, has some common characteristics, such as managing and controlling risks, and analyzing the means and processes of how power and decision making are exercised between the parties involved.

\footnotetext{
${ }^{7}$ The way in which this governance process evolves and its actual/potential impacts on labor and communities is very much at the base of the "Governance of Labor and Logistics for Sustainability" (GOLLS) study. 
For the analysis proposed in this paper we used assumptions made by Barney (2002) as a reference. It is important to emphasize, however, that the analyses by this author apply to the agro-industrial supply chain, while in the present case the açaí productive chain that involves the quilombola communities is an extractive productive chain. As a result, Barney's assumptions about the forms of governance in productive chains were used in a similar and approximate manner, given the specificities of our object of study.

According to Barney (2002), the ideal situation in every potentially valuable economic exchange is for all parties involved to obtain benefits that are equivalent to the work performed, but there is a threat that one party may try to acquire more advantages by exploiting the vulnerabilities of other parties. This refers to the threat of opportunism, which can be damaging to the productive chain.

Opportunism can appear in any commercial exchange; in this case, one party ends up profiting more than it should, and the other party is more likely to be exploited. If there are not enough governance mechanisms in place to minimize opportunism, it can compromise the entire value chain. Governance is a mechanism which can identify and minimize these threats, and sanction the party that wants to benefit from another party's vulnerability. Fines established by the company are one type of governance sanctions, as are fees and other costs attributed to the opportunist or party which breaks bonds of trust and commercial loyalty, so that opportunistic practices are no longer economically appealing.

The governance present in the segment of the açaí production chain we investigated in this study is intermediate governance, which Barney (2002) describes as a relational contract that occurs between the local agents which are part of the chain. For Barney (2002), the relational contract is a form of governance that is based on relationships, trust, friendship, good faith, commitment to ethical issues, and interpersonal relationships between the actors in the value chain. It is a form of low-cost governance that can avoid opportunism, because if one party wishes to take advantage of the others, this trust is shattered. This form of governance reduces transaction costs because there is no need for contractual relationships between parties who trust each other. The parties that comprise the chain work together for a long time, maintaining relationships with strong and lasting bonds.

For this reason, Barney (2002) points out that this mechanism of governance is very common in informal economic exchanges. In this type of exchange there are no contractual relationships established between the parties, and even then opportunistic practices are significantly reduced, since the players must maintain their trust in order to continue the trading process.

This form of governance through relational contracts is visible in the açaí production chain in the state of Amapá where the quilombola communities participate. This was evident in interviews with the extractivists, middlemen, and intermediaries. The middlemen have a trust-based relationship with the communities. This relationship is built through interpersonal relationships, provision of small services, and informal contracts granting production before the harvest, guaranteeing a sale for the extractivist and fruit for the middleman to purchase. Furthermore, some middlemen who are members of quilombola communities also participate in the production chain; this type of relationship is in line with the traditional ways of establishing economic exchanges that we identified within the communities. This relationship of trust can also be seen in economic exchanges between the intermediaries. The other party does not act opportunistically by failing to pay for the fruit because of the mutual trust and continuity of their relationship. The same applies for the intermediaries who receive daily calls about açaí production, including the boatmen who are agents linked to the factories. All sales are informal, and only the relationship between the exporting company and the boatmen is mediated by a formal contract.

Therefore, the relational contract is the preponderant form of governance in the productive chain. The communities tends to sell more of their açaí production to the traders who buy their products every year than to those who appear only during the harvest period. The same occurs between the middlemen and the intermediaries: sales always take place between the same parties, because they have been working together for a long time.

Contract-based sales are not present in the relationships between the communities (producers) and the intermediaries (rural retailers as well as state wholesalers). Interpersonal relationships and bonds of trust and interdependence ultimately engender governance.

Although the breakdown of these informal relationships can reorder the chain, excluding or including agents, we cannot imagine that the governance generated from relational contracts is solely responsible for maintaining these relationships. The agro-extractivists in all the communities we studied complained that the price determined by the middlemen excessively benefits the agents of commercialization, which can be interpreted as opportunism. 
The communities have no opportunity to choose whether to sell their products with or without the middleman. Located in areas with difficult access and lacking the structure or logistical support to ship out their production, these communities are hostage to the commercial logic imposed on them by the rural retailers.

The middlemen claim that the costs of accessing the communities are high, and that prices follow the rules of supply and demand. They recognize that they are the only ones willing to "venture" onto waterways and roads which are precarious and dangerous (especially during the Amazonian rainy season) to get the product to market, which allows them to impose the price. But according to the middlemen, it is the boatmen who benefit most from the chain, since they determine the price of the purchased product at the fair without bearing the costs of transporting the fruit to Amapá's two main urban centers. It is worth mentioning, however, that according to the statement from the middleman himself, the boatmen buy what is left over after sale to the batedeiras.

These allegations by the agro-extractivists and middlemen reveal that the opportunism present in the chain is strongly linked to structural deficiencies and ambiguities in the chain which are found in its connection to local communities. Both groups are uncertain (of sales/contract conditions) and subject to hierarchical power, especially the small-scale farmers. This is combined with the fact that producers from the quilombola communities must contend with subsistence concerns out of season, resource constraints on production (namely transport deficiencies), challenges to their property (due to ambiguous and mixed modes of property rights), and a low level of basic social services.

This leads us to reflect on the performance of another subject that impacts the chain but does not appear if the analysis is limited to the function of the chain and not the determinants that generate its form of governance: the state. In Brazil, the infrastructure conditions to develop markets traditionally derive from state investments. Road construction, port structure, and logistics mechanisms to transport production are among the most extensive public policies carried out by the state. Specifically in Amapá, and in the northern region in general, the açaí chain was not able to attract these structural investments, even despite being part of a global value chain and increasing demand. There are many limitations on the advancement of the extractive market such as high disposal costs, and especially, the lack of infrastructure for production and storage. These limitations create constraints that shape the supply chain and influence its form of governance.

\subsection{Final considerations.}

A subsistence/"primitive" mode of accumulation and mixed mode of territorial rights may work adequately for these traditional communities in situations of stable or moderate demand for their main product (today, açaí). However, the surge in demand has challenged their model of land sharing and ownership, and contractual informality merely serves to underline their sense of dependence on local, regional (and ultimately, global) buyers for this new "wonder product." Many things must change among these extractivists, the community, and in the chain for us to be confident that economic upgrading may emerge and lead to social benefits or improvements.

The social impacts concerning the insertion of the studied quilombola communities in the açaí production chain are reflected in several aspects ranging from the choice of production and the tendency toward monoculture, to income generation and the acquisition of consumer goods and maintenance of living costs. However, we cannot state that an increase in income reported by the agro-extractivists equates to social development. Governance which generates more certainty and sustainable outcomes will require improvements for these extractivists that are local, regional, and span across the entire chain. Until these improvements are implemented, these communities remain vulnerable and relatively voiceless, with no access to basic services such as education, health, water and transportation.

In terms of the broader literature, this study provides further understanding of how important it is to understand chain governance. It uses new research to illustrate the importance of considering the intersection of local (horizontal) conditions and (vertical) chain exigencies. The probability of social inclusion in markets (and in the globalization process) depends on both economic and social upgrading. When this does not occur, power differences may merely be accentuated.

\section{Sponsoring information:}

The research presented in this article was produced within the scope of the GOLLS project (Governance of Labor and Logistics for Sustainability) and financed by Capes/Nuffic through public notice 63/2014. 


\section{References}

Barney, J. (2002).Gaining and Sustaining Competitive Advantage. 2nd ed, -New Jersey. Prentice Hall.

Cardoso e Cardoso, L. F. (2015). The sweat that marks the land: Work, Quilombolas Rights and Territory in the Island of Marajo - Para. In: Revista Ambiente \& Sociedade, v.18 n.2, pp 75 - 92.

Carvalho, A. C. (2010). .Economia dos produtos florestais não-madeireiros no Estado do Amapá: sustentabilidade e desenvolvimento endógeno. 2010. Tese (Doutorado) - Programa de Pós - Graduação em Desenvolvimento Sustentável do Trópico Úmido, Universidade Federal do Estado do Pará, Pará.

Cialdella, N; Alves, L. N. (2014). La ruée vers l' «Açai » (Euterpe Oleracea Mart): Trajectoire d'um fruit emblámatique d'Amazonie. In: Revue Tiers Monde, $n^{\circ}$ 220, octobre-decembre, p 121 - 138.

Durkheim, É. (2002). Lições de sociologia. São Paulo: Martins Fontes,

Gereffi, G; Stark, K. F. (2011). Global value chain analysis: A primer. Durham, North Carolina. Duke University.

Humphrey, J; Schmitz, H. (2014). A Governança em Cadeias Globais de Valor. Retrieved from: <http://webcache.googleusercontent.com>.

IBGE. (2016). Instituto Brasileiro de Geografia e Estatística. Levantamento Sistemático da Produção Agrícola. 2016. Retrieved from: <www.ibge.gov.br>.

Leite, I. B. (2010)Humanidades insurgentes: conflitos e criminalização dos quilombos. In Alameida, Alfredo Wagner Berno de (Org.). Cadernos de debates Nova Cartografia Social: Territórios quilombolas e conflitos. Manaus: Projeto Nova Cartografia Social da Amazônia/UEA Edições.

Locke, J. (1988) Ensaio acerca do entendimento humano. São Paulo: Nova cultural (Os pensadores).

Malcher, M. A. F. (2014). Identidade Quilombola e Território.Retrieved from: <http://observatoriogeograficoamericalatina.org.>.

Pegler, L. (2009)Cadeia Produtivas. In: Dicionário Internacional da outra Economia. Coimbra: Edições Almedina.

Scherer, André Luís Forti. (2015). Cadeias de valor e cadeias globais de valor. Retrieved from: http://www.fee.rs.gov.br.

Santana A.C de, Costa F.A. (2008). Mudanças recentes na oferta e demanda do açaí no Estado do Pará. In: Santana AC de, Carvalho DF \& Mendes AFT (Eds.). Análise sistêmica da fruticultura paraense: organização, mercado e competitividade empresarial. Belém, Banco da Amazônia, p.205-226.

Superti, E; Silva, G. (2014). Patrimônio Cultural Quilombola: "Mapeamento e Publicação do Patrimônio Cultural das 28 Comunidades Quilombolas no Estado do Amapá, certificadas e/ou tituladas pela Fundação Cultural Palmares". Retrieved from: $<$ http://lides.unifap.br/comunidades/> .

Superti, E; Silva, G. (2015). Comunidades Quilombolas na Amazônia: construção histórico-geográfica, características socioeconômicas e patrimônio cultural no Estado do Amapá. In Confins. Revista FrancoBrasileira de Geografia, n 23.

Treccani, G. D. (2006). Terras de Quilombo: caminhos e entraves do processo de titulação. Belém: Secretaria Executiva de Justiça. Programa Raízes. 